\title{
Crafting relations: Aspects of materiality and interactivity in exhibition environments
}

\author{
Sandra Karina Löschke
}

\begin{abstract}
The past decades have seen the early avant-garde's laboratory paradigm and associated exhibition practices re-appropriated by relational art. Both art movements re-evaluate our relationship to the world and to one another and exhibition environments play an important role in the crafting of these relations.
\end{abstract}

Against this background, the paper investigates two aspects of avantgarde practice that touch upon relational aspects in exhibitions: first, the Constructivists' radical re-evaluation of materiality as relations of energies between the physical world and human beings that has been summarised under the heading of faktura; and, secondly, the practical and directed application of faktura in the design of exhibition environments with the objective of producing new relations between audience, art institution and the world.

Using Lissitzky's Hannover and Dresden demonstration rooms as case studies, the paper identifies an inventory of techniques and materials deployed for the construction of what has been considered the first relational environment. It intends to establish a platform for the discussion of trans-historical correspondences that can be detected in contemporary approaches to interactivity and materiality - particularly in art practices associated with relational aesthetics and postproduction art. Does Lissitzky's precedent anticipate, challenge, or offer expansions on current thinking?

\section{Whose laboratory? Experiments with display conventions in relational art as a reprogramming of avant-garde practice}

The metaphor of the 'laboratory' has become synonymous with a tendency in European art venues to experiment with display conventions by staging situations that encourage social exchange in the form of meetings, collective engagement and other activities. In the wider context of contemporary art practice, this concept has been understood to denote interactivity, openendedness, environment and participation (Bishop, 2004, p. 52; Bourriaud, 2002 , p. 9). But neither the use of the term in the context of art, nor its associated practices are essentially new, and suggest trans-historic correspondences with the laboratory years of the early avant-garde, when El Lissitzky and Alexander Dorner collaborated on new exhibition environments with the objective of creating more meaningful relations between art and life, and between the art institution and its audience. During the past decades, Nicolas Bourriaud, 
Maria Lind, Hans-Ulrich Obrist, and other curators who adopted the laboratory paradigm, have reactivated and enmeshed modernist concepts with current debate and practice. Whilst some have consciously re-appropriated historic material to suit their specific aims, others have done so unknowingly. When asked about the influence of people such as Lissitzky and Dorner on her recent projects, Lind, former director of the Kunstverein München, conceded that

Most of us haven't really been aware of these things and have partly reinvented the wheel again. On the one hand this is sad, on the other good not to know everything because that can inhibit you and create a lot of anxiety. However, I think we need to look more at these older projects. (O’Neill, 2011, p. 40)

Whilst Lind regards her historic ignorance as partly liberating, Obrist deliberately frames his curatorial approach as a re-evaluation of avant-garde experimentation. In an endeavour to differentiate himself from the 'white cube' display model of mainstream institutions, he proposes that 'the truly contemporary exhibition should express connective possibilities and make propositions. And, perhaps surprisingly, such an exhibition should reconnect with the laboratory years of twentieth century exhibition practice‘ (Bishop, 2004, p. 51). In What do you expect from an art institution in the 21 st Century?, a publication that served as the general framework of the Palais de Tokyo, Obrist presents his vision for the future art institution as a reprogramming of Dorner's museum model: 1

\section{THE MUSEUM AS TIME STORAGE, KRAFTWERK AND LABORATORY (Alexander Dorner revisited) Alexander Dorner who ran the Hannover Museum in the 1920s defined the museum as a 'Kraftwerk'. He invited artists such as El Lissitzky to realize a contemporary, dynamic display of a museum on the move. (Sans \& Sanchez, 2002, p. 5) ${ }^{2}$}

Rather than seeking historic precedence as a validation of his practice, Obrist is 're-visiting' it from the perspective of the present. Bourriaud theorised this tendency of 're-working' under the heading of postproduction - a theory that describes artworks 'created on the basis of pre-existing works', whereby artists

\footnotetext{
1 The co-directors of the Palais de Tokyo, Jerome Sans and Nicolas Bourriaud, intended the publication as a forum for all those who 'dream of institutions that are different: venue-laboratories, places of adventure, open to all questions, contradictions, risks.' And sought answers from 'certain protagonists of contemporary art and culture' with regards to their expectations from the art institution of the 21st century (Sans \& Sanchez, 2002, p. 5). It appears odd that Bourriaud, author of 'relational aesthetics' - an art theory with a focus on creating relations between people - should seek answers only from a tight circle of curators, artists and other creatives, but not the general public.

2 Obrist continues by stating that Dorner intended 'to transform the neutral white cube in order to assume a more heterogeneous space', to overcome the 'pseudo-neutral space of the nineteenth century which was still prevailing,' and to get to 'functions which accompany a museum today' (Sans \& Sanchez, 2002, pp. 9-10). Obrist's interpretation of Dorner's display strategy as a reaction to the white cube display model - is of course incorrect. The 'white cube' model of display, from which Obrist as well as Bourriaud wish to differentiate themselves, was not common in the nineteenth century, when colourful displays where de rigueur. Even in the 1920s, white museum walls were an exception rather than a rule (e.g. Peter Behrens' white textile screens for the Deutsche Jahrhundertausstellung at the Nationalgalerie Berlin in 1906). The use of white walls in art institutions only established itself in the 1930s (Scholl, 1995).
} 
and curators 'interpret, reproduce, re-exhibit, or use works made by others or available cultural products' (Bourriaud, 2002, p. 13); and Obrist extended this postproduction principle to the re-use of Dorner's museum concept.

Much like Bourriaud's and Obrist's own theories, Dorner's concept of the 'living museum' resulted from his direct engagement with the art and artists of his time and their search for environments that foster interactive experiences rather than institutional representation. The most celebrated of Dorner's museological innovations at the Provinzialmuseum Hannover was the commissioning of Lissitzky's second demonstration room - the Abstract Cabinet. Constructed with cutting-edge industrial materials, this room produced a series of - at times incompatible - tactile and visual effects that were gradually revealed to the viewer as they moved through the space. The use of commercially available coloured metal composites, opaque glass, and artificial light underscored a technology-enhancing curatorial philosophy that sought to overcome man's alienation in an increasingly modernised world and prepare him for the future. In his demonstration rooms, Lissitzky deployed architectural materials to craft new interrelations between art/institution/audience that aimed beyond the context of the museum itself.

\section{Crafting relations: Materiality and interactivity}

The majority of contemporary works produced under the laboratory paradigm converge on strategies of interactivity and audience participation, but contrary to avant-garde practice, the potential role of architectural settings in the shaping of these relations has been largely neglected. Yet, architecture and its material choices form a significant part of the 'curatorial ethos' of such stagings, as Claire Bishop has argued in her critical examination of the Palais de Tokyo, the former Japanese Pavilion of the 1937 World Fair that was converted into a contemporary art venue in 2002 , co-directed by Bourriaud and Jérôme Sans. The aesthetics of its bare, unfinished walls play a significant role in their reconceptualisation of the building from a 'white cube' exhibition model to an 'experimental laboratory' (Bishop, 2004, pp. 51-52). The unfinished character of the interior is not only a key aspect of the building's curatorial concept but also designates the nature of the art that it was intended to accommodate: works with convivial and interactive aspects that produce social encounters which compensate for the fragmentary effects of modernity and mass media.

Bourriaud and Sans see the exhibition space as a scientific 'venue-laboratory' (Sans \& Sanchez, 2002, p. 5) and 'an open stage somewhere between décor, film set, and information centre' whereby the exhibition no longer acts as a medium in itself but 'has become a place of production like any other' (Bourriaud, 2002, 
p. 69). ${ }^{3}$ The perception of the exhibition as a decorative background also arises in the work of Liam Gillick, a frequent collaborator of Bourriaud, Sans, Obrist and Lind. Gillick uses materials and architectural elements that reference the universal modernism favoured in corporate interiors, lobbies and commercial architecture, where 'plexiglas, steel, cables, treated wood, and colored aluminium' connect 'the project of emancipation of the avant-gardes and the protocol of our alienation in a modern economy' (Bourriaud, 2002, p. 58) and prompt the viewer to reflect on a range of at times conflicting environments. ${ }^{4}$ Despite titles like Discussion Island: Project Think Tank, Dispersed Discussion Structure, Prototype Conference Room that imply interactivity and interpersonal engagement, Marcus Verhagen reads these works 'not as the settings for new encounters but as partial images that call to mind a range of other moments and environments' (Verhagen, 2009, p. 52). In this respect, comparisons to avantgarde exhibition practice are possible; like some of Gillick's works, Lissitzky's demonstration rooms call to mind the realities of other spaces of modernity. But they differ from Gillick's architectural references in so far that they do not literally represent physical fragments of other possible spaces, but evoke their sensory reality. The demonstration rooms simulate the experience of modern urban environments in an intensified form: perception in motion, flickering lights, and the visual harshness of industrial environments.

At times, Gillick declares, his work 'doesn't necessarily function best as an object for consideration alone' but simply acts as a 'backdrop or décor rather than a pure content provider' similar to the decorative screens and installations in workplace designs (Bishop, 2004, p. 60). In this respect, Gillick's work fundamentally differs from avant-garde projects, which rejected the notion of material as decoration, or as a simple reference to industrial progress; the avant-garde's central concern was the controlled deployment of commercially available materials to influence audience behaviour and perceptions, often reappropriating techniques and products, which had already been applied in a variety of other fields ranging from advertisements to department store design in innovative ways and to a different effect.

Bourriaud theorises Gillick's appropriations of corporate architecture as postproduction works - works that manipulate materials that are no longer primary:

It is no longer a matter of elaborating form on the basis of a raw material but working with objects that are already in circulation on the cultural market, which is to say, objects already informed by other objects. Notions of originality (being at the origin of) and even of creation (making something from nothing) are slowly blurred in this new cultural landscape marked by

3 It should be noted that Bourriaud's understanding of the art institution as a 'place of production like any other' contrasts with his association of the art institution as a 'scientific laboratory'. The laboratory is a place of modernity, where through artificial intensification and scientific control, the laws of nature and everyday life are suspended - a place unlike other places of production (Felsch, 2005, p. 30).

4 In fact, Gillick has accepted invitations to design the same structures that he intimates in his work: an ornamental façade screen for the entrance of the Home Office London (2002-05), a tasteful interior for the Whitechapel Gallery Café titled 'Adjustment Filter' (2002) and 'Fitting Room' (2004) a design for the Dior Homme Shanghai store, are 
the twin figures of the DJ and the programmer, both of whom have the task of selecting cultural objects and inserting them into new contexts. (Bourriaud, 2002, p. 13)

Bourriaud's theory of postproduction centres on the re-contextualisation of existing objects with the aim of creating alternative scenarios for critical reflection and temporary engagement. He sidelines aspects of originality and invention; his theory concentrates on an object's compensatory capacity for the present rather than its future potential and stands in contrast to the avantgarde's radical reinvention of objects and technologies that was directly linked to progress and innovation.

\section{Re-evaluating materiality as energetic relations: Faktura}

As a response to the major scientific inventions of their time (X-ray, atom, electricity) that had questioned the permanence and solidity of the physical world, ${ }^{5}$ the Constructivists fundamentally re-evaluated their understanding of materiality: transient sensory aspects of materials and their effects on the human unconscious were considered on par with permanent physical qualities and functional and economic implications. Materials were assigned activating and transformative qualities: colours, light and surfaces were seen as pseudotechnical means of influencing human behaviour ${ }^{6}$ - an approach that had already been successfully explored in the art of advertising and that was now expanded to other areas of life. None of these groups has been more engaged with material experimentation and participation than the Constructivists who conceptualised their concerns for materials under the heading of faktura; and no single constructivist work pushed the boundaries of materiality to greater extremes than Lissitzky's exhibition design for the Abstract Cabinet in Hannover.

The Constructivists' concern for faktura as a principle of creative production can be seen as a notion that brought together the arts and crafts on the basic premise of a shared materiality. Industrially produced materials such as metal, glass, nickel, textiles and lacquer were systematically explored in architecture, painting, sculpture, photography and film. Through experimental practice new principles and methods were formulated and systematically applied across all fields of creative production. The main objective was to bring art into life: art had to contribute in a significant way to debates on the fundamental issues of the contemporary world. The immaterial qualities of objects were of equal importance to their material properties and were designed to stimulate

\footnotetext{
5 In the area of science, the discovery of electromagnetic waves, the electron and the atom all offered a radically changed image of matter and space, and promised insights into a superior reality that was outside immediate sensory perception (Henderson, 1998, p. 203). In the areas of physiology and psychology, Wilhelm Wundt's psycho-technical laboratory in Dresden, Ivan Pavlov's physiological laboratory in Leningrad and Freud's psychoanalytical findings provided insights into the unconscious mind (Vöhringer 2007).

6 Wilhelm Ostwald's energetism, which interpreted perception as an interaction of energies between the human organism and materials, and his colour theory were highly influential in constructivist circles and were introduced to de Stijl by Moholy-Nagy's fellow constructivist and Hungarian Vilmos Huszar. Moholy-Nagy's own use of boldly coloured light also brings to mind Ostwald's theories (Gage, 1999, p. 244).
} 
sensations and mediate experiences intended to communicate the cultural and social values of modern society. Consequently, every object had to prove its relevance for civilisation and was designed to enter life as a creative organising force, which would prompt physiological and psychological engagement and facilitate the viewers' adaptation to modern life in post-revolutionary Russia.

In their enthusiasm for material culture and fabrication, the Constructivists set themselves apart from Malevich's suprematism, which was primarily concerned with aesthetic and formal questions. Schuldt underscores the crucial distinction between Malevich and his followers: The practical extent that Malevich assigned to his works was limited to an increased familiarity with potential artistic concepts - his architectural models were about ideas and intellectual values. But the new generation of Constructivists (including Lissitzky and Moholy-Nagy) were interested in materials, techniques and production processes that lead to the development of prototypes with a realistic potential for application (Schuldt, 1965, p. 29).

The first appearance of the phrase 'faktura' can be traced to an article entitled Faktura in David Burliuk's futurist manifesto A Slap in the Face of Public Taste (1912). Only one year later, Mikhail Larionov formulated the theoretical premises for his new style of painting in his 1913 Manifesto of Rayonists and Futurists:

The objects that we see in reality have no relevance for the Rayonist painting. The attention is attracted to the very essence of a painting: combination of colours, their saturation, relationships between the coloured masses, their depth and texture. The painting, in a way slides, gives the sensation of existing outside of time and space, creating the impression of what might be called 'the fourth dimension'. (Dabrowski, 1975, p. 200)

The colour and texture of the surface instigated perceptual interaction and had the capacity to mediate superior sensations that were constructed by the artist by precisely following the laws of colour when transferring paint onto the canvas. ${ }^{7}$ The painting becomes both medium and content, devoid of any reference to the world of objects other than through its own materiality (paint and canvas).

In the following years, more experimental approaches in painting emerged that relied less on the colours of the palette and began constructing surfaces with actual materials instead. Correspondingly, faktura had to be clearly distinguished from the technical device of facture in painting. In a text written in 1916, Nicolai Tarabukin describes the new materials and corresponding artistic principles and competencies:

The form of a work of art derives from two fundamental premises: the material or medium (colours, sounds, words) and the construction, through which the material is organised in a coherent whole, acquiring its artistic logic and its profound meaning [...] The material dictates the forms, and not the opposite. (Rowell, 1978, p. 91)

7 Dabrowksy points to Larionov's early interest in French Impressionism and the colour theories and optical research of Helmholtz and others (Dabrowksy, 1975, p. 205). 
Material assumed the role of both medium and organisational technique: artists had to acquire a developed sense for materiality, a material logic that replaced the traditional artist's craft and skill. Tarabukin's text underscores the quasi-scientific, systematic manner with which artistic production was now pursued that relied on the artist's competence in intellectual interpretation and his capacity to synthesise aesthetic and utilitarian criteria. Benjamin Buchloh maintains that Tarabukin's 'definition of faktura remained essentially valid throughout the entire period of Laboratory constructivism to follow' (Buchloh, 1984, p. 87). Yet, despite its significance to all Constructivist work, it was by no means understood consistently, and within Constructivist circles at INKhUK (Institute of Artistic Culture, Moscow) the interrelations between material, form and function were fervently discussed. The different patterns of voices heard in these deliberations reveal at times incompatible interpretations that highlight technological, psychological or socio-economical positions.

Vesnin suggested that the material and form of an object cannot be arbitrarily changed without destroying the effective operation of the object - its psychological and physiological action on the human consciousness. In order to evoke the 'materialised energy' of objects, the symbiotic relationship between the inner content of materials and their outer properties, or faktura, had to be precisely controlled to generate a connection between the concrete material properties of objects and the spatial energy that they radiate. ${ }^{8}$

Along similar lines, Lissitzky reasons that 'construction represents the endeavour to create special and concrete things, objects. In contradistinction to composition, which only discusses different formal possibilities, construction confirms and accentuates' (Lissitzky-Küppers, 1977, p. 31). He brings his argument to the point by suggesting that the canvas represents the chisel of construction and the brush the instrument of composition. In other words, the new constructivist artwork was deemed to be an object like any other and its making required the precision tools and materials provided by modern science.

For the Russian constructivists 'medium' implied a specific material or surface, and this was specified by the term faktura (Rowell 1978, p. 91). Lissitzky emphasises the mediality of materials in his 1922 Berlin lecture New Russian Art:

Surfaces should be so prepared, chemically and physically, that they capture the true spectral ray and reflect it. Only then, through the differences in wave lengths of the light rays, do we obtain the pure impression of colour. (Railing, 1995, p. 196)

The reference to the treatment of actual materials and surfaces no longer represents abstraction in the sense of a renunciation of the real, but it is an intensification of the real that is brought about by the characteristic appearance of chemical surface treatments (etching, galvanisation, patina, amongst others) and the physical traces of manufacture (cutting or bending). In his article 'EL

8 Patricia Railing points out that the idea of 'energy' or 'force' was a common organising principle among all the definitions of faktura and construction (1995, p. 194). 
Lissitzky', published in Cicerone in 1924, Hungarian critic Ernst Kállai assessed the sensory dimension of faktura in Lissitzky's Prouns as an overlay of the tactile onto the visual: 'The colours are sober white, grey and black. Cutting, steel-hard precision in their processing [Fakturverarbeitung] and their linear delimitation shows how vividly they are experienced' (Kállai, p. 1058). Despite levelling criticism at Lissitzky for creating formal objects without any actual purpose, Kállai's analysis of the Prouns explicitly acknowledges their experiential impact on the viewer.

\section{The potentiality of objects: Faktura as analysis and invention}

After praising the vivacity of the Prouns, Kállai elucidates what he believes is the dilemma of Lissitzky's call for art into life and his endeavour 'to make objects' whilst, in fact, he was 'painting complex forms that look like objects but can be clearly be recognised as fictions'. Lissitzky, Kállai cautions, should not see the 'objectivity of new art in a simply newly-dressed formalism'. If Lissitzky does not want his works to be 'thrown into one pot together with the oil paintings of the museums and the monuments of the generals', then he has to give his objects 'the concrete, real and useful significance through which it distinguishes itself from the category of aesthetic stimulants'. If the call to produce useful objects is brought to its ultimate conclusion, Kállai argues, it means producing actual articles of daily use - chairs, houses and machines (Kállai, p. 1058).

Lissitzky's understanding of 'usefulness' was different - he directed attention away from functionality and towards analysis and invention. In contradistinction to productivist artists like Rodchenko, Lissitzky disapproved of purely functional approaches that resulted in the design of 'primitive utilitarianism' and that, in his opinion, frequently had very little to do with creative effort at all (Margolin, 1997, pp. 33-34). The usefulness of the Proun paintings was to be found in their experimental approach that 'revealed the fundamental elements of threedimensional design through a process of analysis' (Conrads, 1965, p. 10). Although the Prouns are not literally blueprints for future developments, they point beyond the framework of painting towards architecture and the real world.

'For us,' Lissitzky observes, 'the goal exemplifies something which we leave behind. The creative process generates the fact, which becomes the goal.' But he also acknowledges that experimental processes are not necessarily linear when he concedes that at times it happens, that 'one sets off to India and discovers America' (Lissitzky-Küppers, 1977, p. 32). Always in transit between discovery and obsolescence, every object can only be understood as 'preliminary' and this is also clearly expressed in Lissiztky's assessment of his Prouns as an in-between - a 'changing station from painting to architecture' 
(Arp and Lissitzky, 1925, p. xi). His perception of the object as an unstable, dynamic category is based on Lissitzky's understanding of materiality as energy, and he phrases this quite succinctly in his text Proun (1920-21) when he says: 'The relationship of form to material is the relationship of mass to force' (Lissitzky-Küppers, 1977, pp. 28-29). The correlation between material and force, or energy, is also reflected in Lissitzky's concept of immaterial materiality that he described as a dematerialised and imaginary space that transcends physical experience, but nevertheless is real space and can be designed ('gestaltet'). ${ }^{9}$ The idea of immaterial materiality bears witness to Lissitzky's interest in science, mathematics and four-dimensional space. ${ }^{10}$ But how have ideas about materiality informed his choice of materials, architectural concepts and detailing, and how did these activate the viewer? The demonstration rooms represent the most advanced efforts in developing the Proun principles towards architecture and a close analysis of their design should be instructive in answering these questions.

\section{Crafting relations: The Dresden and Hannover demonstration rooms}

Boris Brodsky attributes paradigmatic importance to Lissitzky's exhibition designs and maintains that 'all subsequent experiments in modern art that include the viewer in relation to an environment derive from this first attempt devised by Lissitzky in Berlin in 1923' - the Proun Room. ${ }^{11}$ But Lissitzky's demonstration rooms in Dresden (1926) and Hannover (1927) represent the most developed stage of Lissitzky's use of materials whose sole objective was the activation of the viewer.

The demonstration rooms can be described as experimentation with materiality - a play with rational structures and irrational perceptions which evoke a fluid space set in motion by the viewer. Taking his clue from Eggeling's films, Lissitzky set out to construct a space that, when in a passive state, formed a solid figure in three dimensional space, but when set in motion, emerged as a new object and created new spatial articulations that would exist for the same duration as the movement itself, and therefore was an imaginary space. In K. und Pangeometrie (1925), he concludes his explanation of this imaginary space with the words: 'Here I have pursued the variability of spatial recognition and the corresponding constructions of art and thus have arrived at an immaterial materiality' (Conrads, 1965, p. 129).

\footnotetext{
9 In Lissitzky's writings the idea of an imaginary space and immaterial materiality are expounded in relation to film in his text K. und Pangeometrie from1925 (Conrads, 1965, pp. 128-29).

10 Yve-Alain Bois's essay on reversibility and spatial disorientation in Lissitzky's work is instructive here (Bois, 1988). Also of interest is Esther Levinger's discussion of Lissitzky's interest in mathematics and, in particular, his analogy between imaginary numbers (such as the square root of 1) and imaginary space (Levinger, 1989). 11 Brodsky refers to Lissitzky's Proun Room at the 1923 Great Berlin Art Exhibition, which was his first exhibition design and developed his Proun principle further towards space and architecture (Brodsky, 1980, p. 93). In the late 1920s, Lissitzky abandoned work on Proun and turned his attention to propaganda work for the Soviet state. In this context, Bois's discussion of three distinct creative phases in Lissitzky's work is of interest. Bois outlines these as Chagallian, Suprematist and Stalinist (Bois, 1988).
} 
Schuldt proposes that, in their correspondence to reality, the application of actual materials in the Prouns is comparable to photography. The demonstration rooms develop this reality principle further - they interrogate the boundary between the concrete materiality of architectural prototypes and the immateriality of film. In the demonstration rooms, Lissitzky is achieving the appearance of one (film) with the means of the other (architecture) (Schuldt, 1965, p. 29). The important difference is that the immersive and passive mode of perception in film is almost diametrically opposed to the activating, relational aspects of Lissitzky's exhibition designs, where the physical movement of the viewer takes on the role of the film projector and brings the room to life. And this, as Lissitzky stated in his introduction to the demonstration rooms, was the main objective of the demonstration room. But how precisely is viewer activation achieved through material and architectonic means? The following paragraphs focus on two central elements in the demonstration rooms - the tectonic illumination object and the striated walls.

\section{Constructing with light: The Tectonic Illumination Object}

The second demonstration room - the Abstract Cabinet - occupied a small corner room on the second floor of the Provinzialmuseum Hannover. It was the last room in the museum itinerary and the visitor reached it via the rooms for Expressionism - Room 43 and Room 44. Its two door openings were covered with black fabric curtains. ${ }^{12}$ When the visitor pushed aside the curtains, he faced an illuminated object which covered the entire opposite wall. Lissitzky describes the intended effects of this installation: 'My aim was to transform the window opening into a tectonic illumination object that only admits the amount of light necessary'. ${ }^{13}$ This illumination object transformed the natural daylight of the windows and was divided into three discrete zones (Figure 1).

12 Curtains had been introduced in German museums as part of the museum reform movement to separate rooms that showed artworks of different periods/styles. Although Dorner used curtains throughout the Provinzialmuseum, it should be noted that for Lissitzky the curtains were an integral part of the overall design of his room. Already in 1923, Lissitzky described a curtain for a theatre stage set as representing Malevich's 'black square': 'der Vorhang=schwarzes Quadrat' in his text Die plastische Gestaltung der elektromechanischen Schau 'Sieg über die Sonne' (Conrads, 1965, p. 118).

13 Lissitzky, ca. 1926, 2 'Demonstrationsräume', typescript, Nachlass Alexander Dorner, Sprengel Museum, Hannover/Germany. 


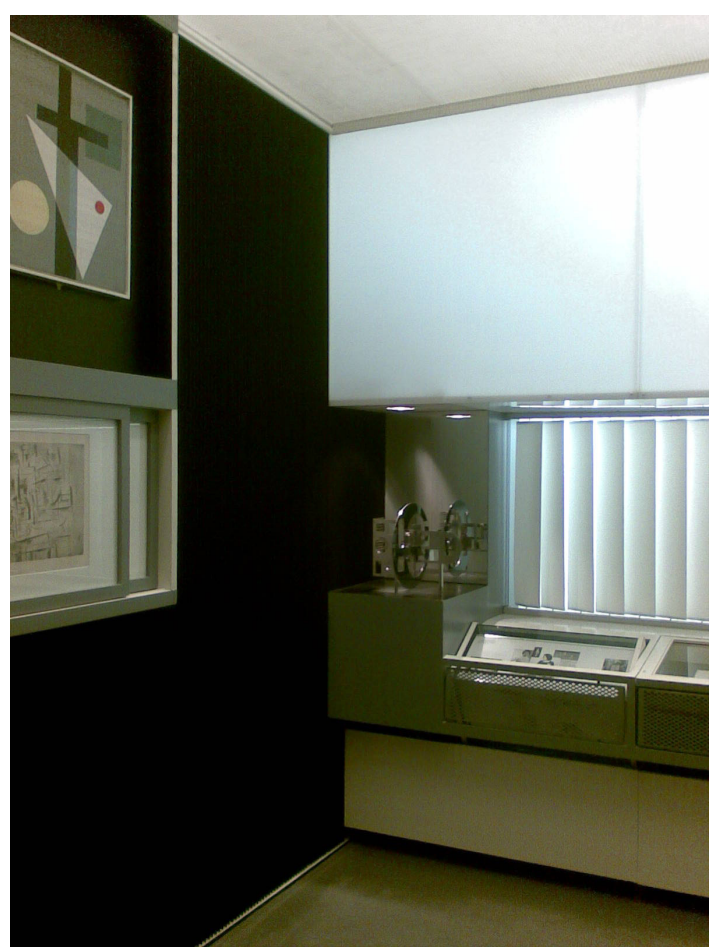

Figure 1. 1968 Reconstruction of the Abstract Cabinet at the Sprengel Museum Hannover/Germany, 2009.

Source: Author.

The upper part of the object had been designed as a light box made of glass covered in white muslin fabric and providing even illumination from above. Adjustable vertical fabric blinds were installed across the middle zone. These were recessed so that the light box above assumed a floating, weightless appearance. In the set of specification drawings prepared for the room, the vertical louvres are shown tilted in two opposite directions: 30 degrees to the right and to the left respectively, so that the incoming light would be directed at the two walls on either side. ${ }^{14}$ They could be adjusted to carefully control the amount of illumination necessary relative to external lighting conditions. Two illuminated glass display cases occupied the third zone below the louvres, which contained horizontally rotating cubes intended for watercolours. ${ }^{15}$ The use of fabric as a light-transmitting material is of great importance - real materials (including natural daylight) had to be transformed artistically, their faktura had

14 The original title of the drawing is 'Entwurf Schaukabinett Hannover, Fensterwand'.

15 Whilst the typescript of Lissitzky's introduction to the demonstration rooms states that the rotating cubes in the glass cases are intended for the display of watercolours, Dietrich Helms remembers that the cases contained text and images for a history of the evolutionary development of architecture (Helms and Dorner, 1963, p. 144). A content description of the Abstract Cabinet, titled 'Kunstmuseum Hannover mit Sammlung Sprengel', hand-dated 'August 1979' and held at the Sprengel Museum Archive, also describes the display cubes as containing texts from Alexander Dorner for the initial cabinet. 
to be brought to life. Moholy-Nagy formulated it thus: 'Light, if rendered into art, must first be transmitted and transformed through materials - not projected directly at the viewer' (Kostelanetz, 1971, p. 160).

The vertical fabric blinds highlighted the dynamic character of light by not only providing general illumination and controlling the amount of light admitted but by also regulating its direction. 'The light,' Lissitzky said in his introduction to the demonstrations rooms, "which is only generated through the effects of colour, shall be controlled.'16 Originally, he had planned to use electric lighting, which would vary periodically, but this plan could not be realised because electrical connections were not available at the Provinzialmuseum. The introduction of rhythmically changing light would have doubtlessly served to animate the visitors by directing their attention to various parts of the room and inviting them to engage with the space.

The tectonic illumination object is a further development of the lighting strategy deployed in the earlier Dresden demonstration room, where the full expanse of the ceiling was covered with stretched muslin, and back-lit with electric lights that provided an even illumination for the room below. In Dresden, Lissitzky had experimented with coloured light: overlaying the ceiling along one end wall with blue and the other with yellow resulted in one wall being 'coldly lit, the other warmly'. ${ }^{17}$ In his colour choices for the lights Lissitzky diverged from the Suprematist colour palette of black, white and red to attain psycho-perceptual effects. Blue-yellow was one of the opposing colour pairs of Ewald Hering's colour theory, and together the two colours were thought to produce white light - the colour of space in Suprematism.

\section{Activating the viewer: Mediality and materiality in the iridescent wall}

... to be welcomed is the eye of the architect, that shows us a series of known objects in such a way that we are prompted to reconsider these more profoundly. Architekt El Lissitzky. (Lissitzky-Küppers, 1977, p. 69)

In the manuscript of his 1926 introductory text, 2 Demonstrationsräume, Lissitzky states that the main objective for the demonstration rooms was the activation of the viewer, and this demanded the creation of the best possible optical conditions, comparable to the acoustics of a concert hall. These optical conditions were achieved through the treatment of the walls. Samuel Cauman describes these as producing 'a cool shimmer that changed with the slightest movement of the visitors head' (1958, p. 104). The walls consisted of $40 \mathrm{~mm}$ vertical steel bands set at right angles to the wall at $20 \mathrm{~mm}$ centres. The bands

16 Lissitzky, ca. 1926, 2 'Demonstrationsräume', typescript, Nachlass Alexander Dorner, Sprengel Museum, Hannover/Germany.

17 Lissitzky, ca. 1926, 2 'Demonstrationsräume', typescript, Nachlass Alexander Dorner, Sprengel Museum, Hannover/Germany. 
were recessed into a $10 \mathrm{~mm}$ painted timber panel which formed the visual backdrop. Similar to the concept of the Dresden demonstration room, which had used timber slats, the steel bands were painted grey on the front edge, white on the left side and black on the right side. According to the position of the viewer, the walls would have three lives, appearing white, grey or black. But because in Hannover the major source of light came from the side and not from above as in Dresden, Lissitzky varied the sequence of tones in different sections of the wall, stimulating the visitor to move around. Moving towards the illuminated glass display case, he noticed the change in the coloration of the wall sections either side. The colours of the first section on wall 3 initially appeared grey, gradually darkened to black and finally emerged white, thus representing a complete inversion of the tonal scale. The colours of the second section on wall 3 followed a different pattern - after initially appearing black they gradually lightened to white and then turned grey (Figure 2). The variation in colours corresponded to a variation in depth perception of the viewer, whereby black receded from the viewer and white advanced towards them, grey occupying the middle ground. Since the sequences varied on all walls the space seemed to fluctuate creating an effect of destabilisation and disorientation.

The most significant innovation in Hannover was the introduction of ultrathin steel bands that replaced the evenly spaced $70 \mathrm{~mm}$ timber slats of the Dresden room. ${ }^{18}$ Lissitzky used a staggering 1288 linear metres of what was an innovative material at the time, Nirosta steel. A chromium nickel alloy, Nirosta was not strong enough as a structural material, and its manufacturer, Krupp Stahl, had used it as an architectural cladding panel for both interior and exterior applications. ${ }^{19}$ By turning the steel sheet on its edge, Lissitzky inverted its role as a wall panel and turned it into an element that destroyed any illusion of surface. In the Abstract Cabinet, Nirosta no longer functioned as a real utilitarian construction material but as a tactile and optical animation device.

18 The Dresden demonstration room has frequently been omitted from historical accounts of Lissitzky's work, as Nikolaus Pevsner pointed out in his letter to the editor of Art Journal (Pevsner, 1971, p. 128). The former director of the Provinzialmuseum in Hannover, Dorner, does not mention the Dresden precedent and incorrectly pre-dates the Hannover room to 1925, which implies that it would have been built prior to the Dresden room which was constructed in 1926 (Dorner, 1958).

19 Maria Gough provides a detailed discussion of Nirosta steel and its uses (Gough, 2003, p. 101). 


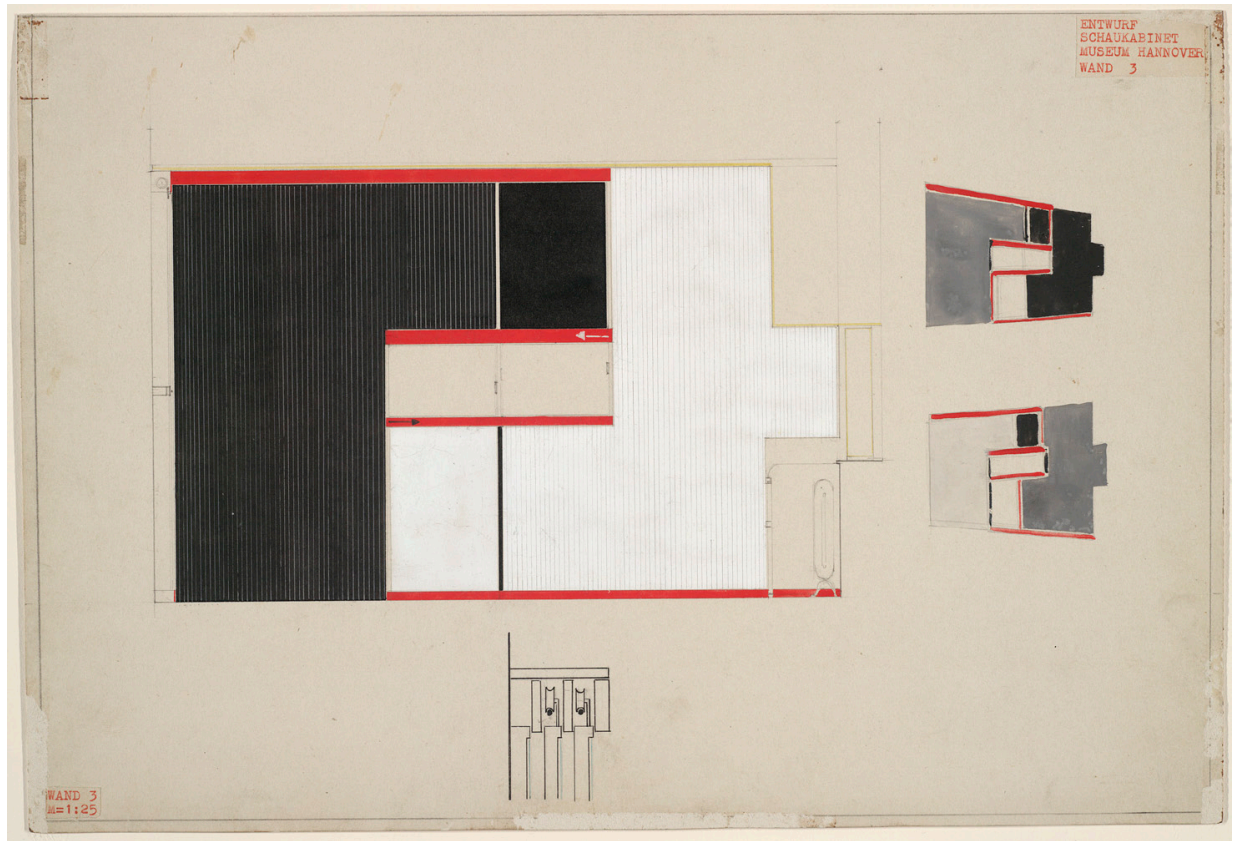

Figure 2. El Lissitzky, Entwurf Schaukabinett Museum Hannover - Wand 3 (Design for Exhibition Room in the Hanover Museum), 1926, graphite, gouache, metallic paint, black and red ink and typewritten labels, 24.9 x $36.5 \mathrm{~cm}$. Harvard Art Museums/ Busch-Reisinger.

Source: Imaging Department. President and Fellows of Harvard College.

Critics have expressed their perplexity at the fact that Lissitzky decided to paint the steel bands, arguing that 'in themselves, along with the clefts of shadow cast by them, they would have produced a comparable effect of spatial destabilisation' (Gough, 2003, p. 123). Yet the use of colours intensified the light and shadow effect of the wall and, with only one light source available in Hannover, the desired variation in the sequence of colours could not have been achieved with light and shadow alone. Lissitzky's interest seems to have been less in the surface qualities of the steel than in its thinness. The use of an industrially manufactured material as opposed to traditional timber produced a much higher degree of precision. The Nirosta was only $0.8 \mathrm{~mm}$ thick, and effectively reduced the front edge of the steel band to the optical thinness of a two-dimensional line and thus dissolved the surface of the wall. In an annotated detail sketch for the steel bands, Lissitzky denotes their size as $40 \mathrm{~mm} \times 1 \mathrm{~mm}$, but adds in brackets 'or $0,8^{\prime}$ indicating his desire to reduce the already minimal width of the steel even further. ${ }^{20}$

In a frontal view, the striation of the bands is most obvious and the thin bladelike quality of the steel articulates the hardness and the sharpness of the material. The ultrathin edge and the narrow spacing of the bands dissolves the wall surface into an electric flickering - much like the flicker of Eggeling's early 
avant-garde films, or the flicker of the visual stimuli of neon lights that could be witnessed in the modern city. In contrast, a completely oblique view allows the colours to coalesce as a deep black or luminous white colour field, making the room appear infinitely deep in the first instance and intimate and softly glowing in the second. The visual harshness of the flicker on one hand, and the soft luminous colour field on the other hand, might have lead Conrad Buchwald to describe the wall as reminiscent of an 'operating theatre' and a 'padded cell' at the same time, hinting at the optical and tactile effects which - pleasurably and painfully - made the viewer aware of the act of seeing. Emphasising its playful character Buchwald describes the whole room as 'an object of dalliance' in his exhibition review that appeared in Schlesische Zeitung of 19 June 1926 (Hemken, 1990, p. 47). Despite this perceived playfulness, it is possible to discern design principles that might have been informed by scientific insights in optical science and gestalt theory. Although Lissitzky never explicitly references scientific sources, well-known optical phenomena such as the ambiguity of figure/ground relationships, chromatic augmentation and assimilation can be readily identified in the walls: from an increasingly oblique view, the grey front edge of the steel band begins to appear lighter against the black side of the band (Figures 3a, 3b, 3c). When the visitor looks in the other direction, this effect is reversed and the grey edge appears darker against the white side, because the eye augments the difference between the edge colour and the side colour. Thus the different colour sequences and view angles create subtly varied optical sub-effects. This impression of 'flickering energy' in the Abstract Cabinet is fundamentally different to the timber slats used in the Dresden room, where the front face of the timber and the visible wall face of the background were of equal width and were perceived as alternating coloured surfaces, which could be equally seen as background or foreground. In this respect the use of faktura in the Dresden room retains a certain painterly effect compared to the harsh, electronic flicker of the cabinet. 

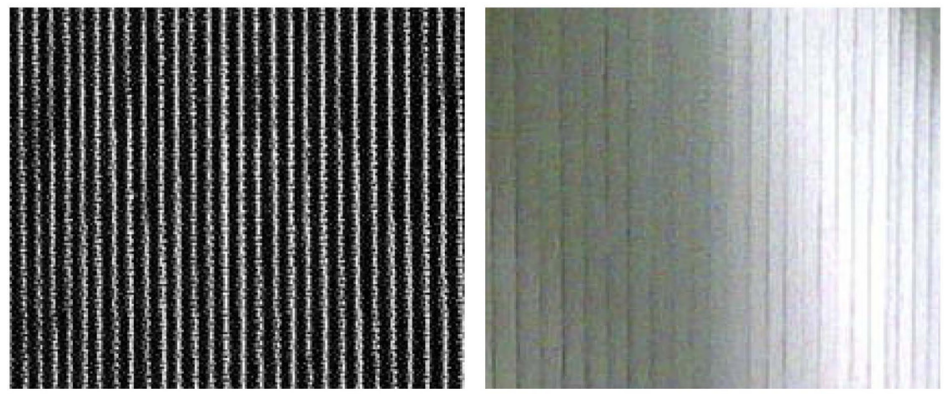

Figure 3a. Photographic details of the 1968 reconstruction of the Abstract Cabinet at the Sprengel Museum Hannover showing the changing appearance of the steel wall: visual harshness (left) and soft luminosity (right), 2009.

Source: Author.
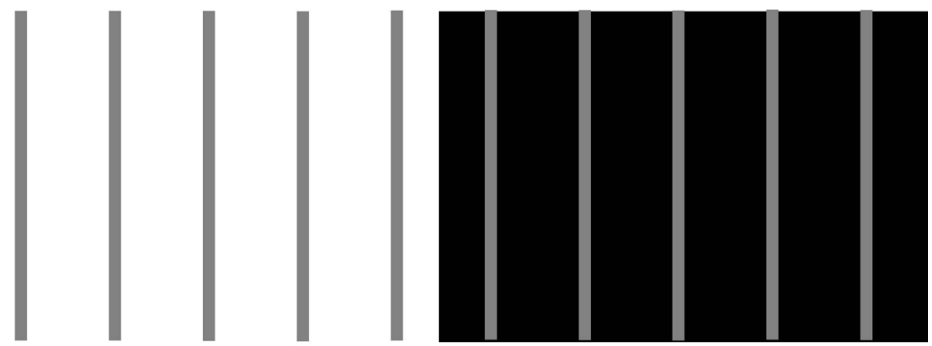

Figure 3b. Optical effects-colour augmentation, 2009. The grey edge appears darker on a grey background (left). The grey edge appears lighter on a black background. The eye augments the difference between the edge and what appears to be its background.

Source: Author.
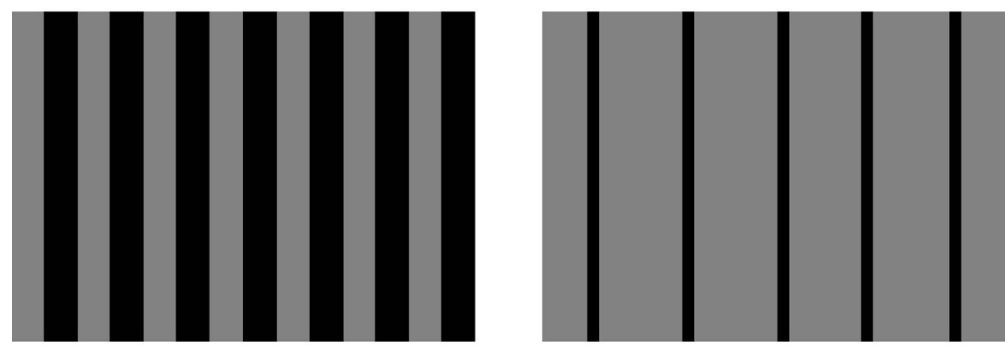

Figure 3c. Optical effects-figure/background, 2009. Both the black and the grey stripes can be interpreted as figure. The figure/ground relationship is ambiguous because the stripes are equal width (left). The narrower stripes are figure. The determining factor for the figure/ground relationship is not colour but relative size.

Source: Author. 


\section{Conclusion}

Lissitzky's exhibition designs elevated materiality from a mere background function to the actual thematic focus of the exhibition. The faktura of the room (energy emanating from colours, light and surfaces) stimulated the visitor's movement and gave rise to intense and at times conflicting sensory experiences that were intended to engage the visitor intellectually by making him reflect about the modern world, where tactile and visual senses were no longer opposed. Lissitzky thus translated the sensory experiences of the industrialised and media-dominated urbanity into an architectural prototype, not with the intent of creating chaos, but to acquaint the viewer with these new conditions and the requirements they posed for an even more intensely technicised future.

Projects associated with relational aesthetics and postproduction art such as Gillick's Övnigskörning (Driving practice, 2004) (Gillick and Haberer, 2002, pp. 3334) are comparable to Lissitzky's in terms of material palette, processural aspects and the objective of producing new relations, and this paper intends to offer the basis for a more informed discussion of how Lissitzky's precedent anticipates, challenges, or offers expansions on examples of contemporary practice.

Sandra Löschke is an architect and studied at the Architectural Association and the Bartlett/University College London. Her research focuses on materiality and mediality in modern exhibition architecture. Since 2010, Sandra has been a lecturer on architecture and culture and leads the materiality laboratory at UTS.

\section{Glossary of terms and abbreviations}

INKhUK Institute of Artistic Culture, Moscow

PROUN Project for the affirmation of the new (Proekt utverzhdenia novogo)

All translations from German are my own.

\section{Bibliography}

Arp, H. and Lissitzky, E., 1925, Die Kunstismen, Erlenbach-Zürich, München and Leipzig: Eugen Rentsch Verlag

Bishop, C., 2004, 'Antagonism and Relational Aesthetics', October, no. 110, pp. $51-79$

Bois, Y.-A., 1988, 'El Lissitzky: Radical Reversibility', Art in America, vol. 76, no. 4, pp. 160-81

Bourriaud, N., 2002, Postproduction, Berlin/New York: Sternberg Press 
Brodsky, B., 1980, El Lissitzky, Washington, D.C., Los Angeles: Los Angeles County Museum of Art and Hirshhorn Museum and Sculpture Garden, Smithsonian Institution.

Buchloh, B.H.D., 1984, 'From Faktura to Factography', October, vol. 30, pp. 82-119

Cauman, S., 1958, The Living Museum: Experiences of an Art Historian and Museum Director - Alexander Dorner, New York University Press

Conrads, U., 1965, Rußland: Architektur für eine Weltrevolution, Berlin Frankfurt/M. Wien: Ullstein

Dabrowski, M., 1975, 'The Formation and Development of Rayonism', Art Journal, vol. 34, no. 3, pp. 200-07.

Dorner, A., 1958, The Way Beyond Art, New York University Press

Felsch, P., 2004, ‘Das Laboratorium'. In: A. Geisthövel, H. Knoch eds, Orte der Moderne: Erfahrungswelten des 19. und 20. Jahrhunderts, Frankfurt/New York: Campus Verlag

Gage, S., 1999, Colour and Meaning: Art, Science and Symbolism, London: Thames and Hudson

Gillick, L. and Haberer, L., 2007, factoriesinthesnow, Zurich: JRP Ringie

Gough, M., 1998, 'In the Laboratory of Constructivism: Karl loganson's Cold Structures', October, vol. 84, pp. 90-117

Gough, M., 2003, ‘Constructivism Disoriented: El Lissitzky's Dresden and Hannover Demonstrationsräume'. In: N. Perloff, B. Reed eds, Situating El Lissitzky: Vitebsk Berlin Moscow, Los Angeles: Getty Research Institute

Helms, D. and Dorner, L., 1963, 'The 1920's in Hannover: An Exhibition in Hannover, Germany', Art Journal, vol. 22, no. 3, pp. 140-44

Hemken, K.-U., 1990, 'Pan-Europe and German art: El Lissitzky at the 1926 Internationale Kunstaustellung in Dresden'. In: J. de Bout ed., El Lissitzky 1890-1941: Architect, painter, photographer, typographer, Eindhoven: Municipal van Abbemuseum

Henderson Dalrymple, L., 1998, Duchamp in Context - Science and Technology in the Large Glass and Related Works, Princeton University Press

Kállai, E., 1924, 'El Lissitzky', Der Cicerone, vol. XVI, pp. 1058-63

Kantor, S.G., 2002, Alfred H. Barr and the Intellectual Origins of the Museum of Modern Art, Cambridge, Massachusetts and London, England: MIT Press

Kostelanetz, R., 1971, Moholy-Nagy, London: Allen Lane 
Levinger, E.,1989, 'Art and Mathematics in the Thought of El Lissitzky: His Relationship to Suprematism and Constructivism', Leonardo, vol. 22, no. 2, pp. 227-36

Lissitzky, E., 1925, Entwürfe für den Raum der Abstrakten Kunst im Provinzialmuseum Hannover 1927, specification drawings held at the BuschReisinger-Museum, Harvard University, Cambridge Massachusetts

Lissitzky, E. ca., 1926, 2 Demonstrationsräume, typescript, Nachlass Alexander Dorner, Sprengel Museum, Hannover/Germany

Lissitzky, E. undated, Skizze Eisenbänder, Nachlass Alexander Dorner, Sprengel Museum, Hannover/Germany

Lissitzky-Küppers, S. and Lissitzky, J., 1977, Proun und Wolkenbügel Schriften, Briefe, Dokumente, Dresden: VEB Verlag der Kunst

Lodder, C., 2005, Constructive Strands in Russian Art 1914-1937, London: The Pindar Press

Margolin, V., 1997, The Struggle For Utopia: Rodchenko, Lissitzky, Moholy-Nagy 1917-1946, Chicago and London: University of Chicago Press

O’Neill, P., 2011, 'Going Beyond Display - the Munich Kunstverein Years', On Curating, no. 9, pp. 39-42

Pevsner, N., 1971, 'The Lissitzky Room', Art Journal, vol. 31, no. 1, p. 128

Railing, P., 1995, 'The Idea of Construction as the Creative Principle in Russian Avant-Garde Art', Leonardo, vol. 28, no. 3, pp. 193-203

Rowell, M., 1978, 'Vladimir Tatlin: Form/Faktura', October, vol. 7 (Soviet Revolutionary Culture), pp. 83-108

Sans, J. and Sanchez, M., 2002, What Do you Expect from an Art Institution in the 21st Century?, Paris: Palais de Tokyo

Scholl, J., 1995, 'Funktionen der Farbe. Das Kronprinzenpalais als farbiges Museum'. In A. Joachimides, S. Kuhrau, V. Vahrson, and N. Bernau eds., Museumsinszenierungen: Zur Geschichte der Institution des Kunstmuseums - Die Berliner Museumslandschaft 1830-1990, Dresden: Verlag der Kunst

Schuldt, 1965, 'El Lissitzky's Photographische Arbeiten'. In J. Leering, W. Schmied, El Lissitzky,Stedelijk van Abbemuseum, Eindhoven and Kestner Gesellschaft, Hannover

Verhagen, M., 2009, 'Conceptual Perspex'. In M. Szewczyk S. Kalmar, D. Molon, B. Ruf, and N. Schafhausen eds, Meaning Liam Gillick, Cambridge, Massachusetts: MIT Press

Vöhringer, M., 2007, Avantgarde und Psychotechnik: Wissenschaft Kunst und Technik der Wahrnehmungsexperimente in der frühen Sowjetunion, Göttingen: Wallstein Verlag 